\title{
Electroconductive Additives for High-Rate Capability of High-Areal-Capacity Lithium-Sulfur Batteries Using Metal-Foam Current Collector
}

\author{
Hiroki Nara, Tokihiko Yokoshima, Hitoshi Mikuriya, Shingo Tsuda and Tetsuya Osaka,* \\ Research Organization for Nano \& Life Innovation, Waseda University, 513 Wasedatsurumaki-cho, \\ Shinjuku-ku, Tokyo 162-0041 Japan; h-nara@aoni.waseda.jp (H.N.); t.yokoshima@aoni.waseda.jp (T.Y.); \\ h.mikuriya@aoni.waseda.jp (H.M.); tsuda.s@aoni.waseda.jp (S.T.) \\ * Correspondence: osakatets@waseda.jp; Tel.: +81-3-5286-8059
}

\begin{abstract}
Various types of electroconductive additives were evaluated for high C-rate capability in an attempt to extend practical application of high-areal-capacity lithium-sulfur batteries that employ an aluminum-foam current collector. Carbon nanofibers (CNFs) were found to be the most effective additive, with the ability to attain a high-sulfur-loading of $40 \mathrm{mg} \mathrm{cm}^{-2}$. A CNF-containing cell exhibited gravimetric capacities of 1094 and $758 \mathrm{mAh} \mathrm{g}_{\text {sulfur }}{ }^{-1}\left(46.8\right.$ and $\left.32.4 \mathrm{mAh} \mathrm{cm}^{-2}\right)$ at 0.05 and $0.1 \mathrm{C}$-rate, respectively, in an ether-based electrolyte. Because a CNF-containing slurry exhibits low viscosity even at a high solid ratio, it could be filled into the aluminum foam. Additionally, a lithium-sulfur battery with high-sulfur-loading had an energy density of $\sim 120 \mathrm{Wh} \mathrm{kg}^{-1}$, a value that was calculated from the weight of the components of the cathode, anode, current collectors, electrolyte, and separator. Assuming that the amount of electrolyte decreases and that the energy density of cells accumulate, a theoretical energy density of $522 \mathrm{Wh} \mathrm{kg}^{-1}$ was estimated. Moreover, it was found that even if a high-areal-capacity was achieved, the discharge capacity converged at a high C-rate, unless there was an improvement in ion diffusion in the bulk electrolyte. This is considered a limitation of sulfur cathodes with high-sulfur-loading.
\end{abstract}

Keywords: Electroconductive additive; Sulfur cathode; Aluminum-foam current collector; Areal capacity; C-rate capability; Lithium-ion battery

\section{Introduction}

Since the practical realization of lithium-ion batteries (LIBs) in $1991^{1}$, their application range has grown wider and wider because of the continuous increase in their energy density. Although LIBs were used in small electronic devices such as cellular phones, video cameras, and laptop computers in the early days, they are currently widely used in electric vehicles, and stationary batteries are now capable of storing power generated by solar and wind sources. The wider application of LIBs requires them to be safe, low-cost, and in possession of high energy density. Sulfur is one of the promising cathode materials to help LIBs meet these requirements because it has low toxicity, is produced as an industrial byproduct, is abundant in nature ${ }^{2}$, and has high theoretical capacity $\left(1675 \mathrm{mAh} \mathrm{g}^{-1}\right)^{3,4}$. Although the operating potential of sulfur is low, its high theoretical capacity sufficiently compensates for the shortcoming. Owing to the high theoretical capacity of sulfur, lithium-sulfur batteries are expected to have a theoretical energy density of $2500 \mathrm{Wh} \mathrm{kg}^{-1}$ (or $2800 \mathrm{Wh} \mathrm{L}^{-1}$ ) ${ }^{2,3}$, which is very high when compared with that of $387 \mathrm{Wh} \mathrm{kg}^{-1}$ for conventional graphite- $\mathrm{LiCoO}_{2}$ batteries. However, some barriers, such as low ionic and electrical conductivity, large volume expansion upon lithiation from $\mathrm{S}_{8}$ to $\mathrm{Li}_{2} \mathrm{~S}$ (approximately $180 \%$ ), solubility of polysulfides, $\mathrm{Li}_{2} \mathrm{~S}_{x}(4 \leq x \leq 8)$, into the electrolyte solution ${ }^{5}$, and low sulfur loading in the cathode ${ }^{6}$, hinder its practical use. The dissolution of polysulfides in the electrolyte solution results in low charge-discharge efficiency (known as the shuttle effect), self-discharge, and capacity decay. Nazar and co-workers proposed a solution to 
overcome the problems associated with a sulfur cathode, namely using an ordered mesoporous carbon material as a host for sulfur to improve the low ionic and electrical conductivity and to prevent polysulfide dissolution ${ }^{3}$.

Many studies have been conducted to tackle the problem of polysulfide dissolution by using carbon materials to physically or chemically (or both physically and chemically) adsorb the polysulfides ${ }^{3,7}$, by using ionic-conductive polymers to suppress migration of the polysulfides ${ }^{8-10}$, and by using semi-conductive or metallic oxides to adsorb the polysulfides owing to their high polarity 11,12. Other approaches to tackle the polysulfide dissolution include using electrolytes such as glymebased ionic liquids ${ }^{13}$, which shows sparingly solubility against the polysulfides ${ }^{14}$, and by using an additive such as $\mathrm{LiNO}_{3}$, which forms a protective layer on the lithium metal anode to suppress the polysulfide reduction on the anode, impeding the shuttle effect ${ }^{15}$.

As described above, sulfur cathodes have been progressing toward practical application. As their development advanced, the low sulfur loading in the cathode and low sulfur loading ratio in the entire cathode have emerged as limiting factors ${ }^{6}$. The problem of low sulfur loading has been emphasized by the revelation by Hagen et al. that the areal sulfur loading of most sulfur cathodes is less than $2.0 \mathrm{mg} \mathrm{cm}^{-2} 16$. Meanwhile, Gao et al. pointed out that if a lithium-sulfur battery has a sulfur loading ratio in a cathode of less than $\sim 70 \%$, its volumetric energy density will be lower than that of a conventional lithium-ion battery ${ }^{17}$. As a means to increase the sulfur loading in a cathode, Zhou et al. reported promising results by using graphene foam as the current collector; they also investigated the relationship between the sulfur loading and areal capacity ${ }^{6}$, reporting a high sulfur loading of $10.1 \mathrm{mg} \mathrm{cm}^{-2}$ with corresponding high areal capacity of $13.4 \mathrm{mAh} \mathrm{cm}{ }^{-2}$. For practical application of this approach, however, graphene foam must be produced on a large scale. Furthermore, Chen et al. reported a high sulfur loading of $15.6 \mathrm{mg} \mathrm{cm}^{-2}$ with corresponding high areal capacity of $8.6 \mathrm{mAh}$ $\mathrm{cm}^{-2}$ by using $\mathrm{Ti}_{4} \mathrm{O}_{7}$ nanoparticle-embedded porous carbon host of sulfur on a nickel foam current collector. ${ }^{18}$

In our recent work, we demonstrated an unprecedented high areal capacity of $21.9 \mathrm{mAh} \mathrm{cm}^{-2}$ with $0.01 \mathrm{C}$-rate for discharge by using an aluminum-foam current collector and a binder consisting of carboxymethyl cellulose (CMC) and styrene butadiene rubber (SBR) ${ }^{19}$. To attain such a high areal capacity, it is important to fill the aluminum foam with a high-solid-ratio slurry. In the study presented here, the areal capacity and rate capability of a sulfur cathode with an aluminum-foam current collector were improved by selecting appropriate the electroconductive material, whose manufacturing process is established (commercially available), and electrolyte. The possibility to enhance the energy density of the lithium-sulfur battery was also investigated.

\section{Results and discussion}

Pieces of aluminum foam with high sulfur loading were prepared by filling them with slurries composed of the S-KB composite, $\mathrm{CMC}+\mathrm{SBR}$ binder, and different electroconductive additives: $\mathrm{AB}$, $\mathrm{KB}, \mathrm{CNTs}$, CNHs, or CNFs as commercially available carbons. Among the various combinations, the slurry containing CNFs had a viscosity that was sufficiently low for it to be filled into the aluminum foam at a relatively high solid ratio because of its small specific surface area, as summarized in Table 1; therefore, a S-KB based cathode with high sulfur loading in the aluminum foam was successfully obtained. The viscosities of the slurries with high solid ratio, which consisted of the other electroconductive additives, were too high, and these slurries could not be properly filled into the aluminum foam. As examples, Table 2 shows the viscosities of slurries with different solid content and containing $\mathrm{KB}$ or $\mathrm{CNF}$ as the electroconductive additives.

Table 1. Specific surface area of the electroconductive additives.

\begin{tabular}{cccccc}
\hline & $\mathrm{AB}$ & $\mathrm{KB}$ & $\mathrm{CNTs}$ & $\mathrm{CNHs}$ & $\mathrm{CNFs}$ \\
\hline $\begin{array}{c}\text { Specific surface area } \\
\left(\mathrm{m}^{2} / \mathrm{g}\right)\end{array}$ & $30-150$ & 1270 & $250-300$ & $1300-1400$ & 13 \\
\hline
\end{tabular}


Table 2. Viscosity of slurries with different solid content and containing KB or CNFs as the electroconductive additive.

\begin{tabular}{|c|c|c|}
\hline \multirow{2}{*}{$\begin{array}{c}\text { Solid ratio ( } \\
\text { wt.\%) }\end{array}$} & \multicolumn{2}{|c|}{ Viscosity $(\mathrm{mPa} \cdot \mathrm{s})$} \\
\hline & $\mathrm{KB}$ & CNFs \\
\hline 15 & $10.5-10.6$ & N/A \\
\hline 20 & $40.8-41.5$ & $13.4-14.1$ \\
\hline 25 & $3370-3380$ & N/A \\
\hline 30 & N/A & $90.0-95.0$ \\
\hline 40 & N/A & Over range $\quad(>10000)$ \\
\hline
\end{tabular}

Next, we investigated the C-rate capability of the highly loaded sulfur cathodes with different electroconductive additives $-\mathrm{AB}, \mathrm{KB}, \mathrm{CNTs}, \mathrm{CNHs}$, and CNFs. Among the five electroconductive additives, KB and CNFs had the largest effect on the sulfur loading and exhibited better C-rate capability. Fig. 1 illustrates typical charge-discharge curves obtained at various $\mathrm{C}$-rates for the cells composed of $\mathrm{KB}$ and $\mathrm{G} 1+\mathrm{G} 3$ (i.e., the KB- $(\mathrm{G} 1+\mathrm{G} 3)$ cell), $\mathrm{CNFs}$ and $\mathrm{G} 1+\mathrm{G} 3$ (i.e., the $\mathrm{CNF}-(\mathrm{G} 1+\mathrm{G} 3)$ cell), and $\mathrm{CNF}$ s and DOL+DME (i.e., the $\mathrm{CNF}-(\mathrm{DOL}+\mathrm{DME})$ cell) as the electroconductive additive and electrolyte, respectively. For the discharge curves of the KB-(G1+G3) cell with sulfur loading of 15 $\mathrm{mg} \mathrm{cm}-2$, the following behavior, which is typical of a sulfur cathode, was confirmed 3,20: $\mathrm{S}_{8}$ was converted to $\mathrm{Li}_{2} \mathrm{~S}_{x}$ (where $x=3-8$ ) at $\sim 2.10 \mathrm{~V}$, and $\mathrm{Li}_{2} \mathrm{~S}_{x}$ was converted to $\mathrm{Li}_{2} \mathrm{~S}$ at $\sim 2.05 \mathrm{~V}$. The cell delivered gravimetric capacities of 1354 and 1251 milliampere hour per gram of sulfur $\left(\mathrm{mAh} \mathrm{g}_{\text {sulfur }}{ }^{-1}\right)$ at C-rates of 0.01 and $0.02 \mathrm{C}$, which are equivalent to areal capacities of 21.3 and $19.7 \mathrm{mAh} \mathrm{cm}{ }^{-2}$, respectively. For the discharge at higher $\mathrm{C}$-rate, the second plateau that represents the conversion of $\mathrm{Li}_{2} \mathrm{~S}_{x}$ to $\mathrm{Li}_{2} \mathrm{~S}$ was hardly confirmed. On the other hand, for the discharge curves of the $\mathrm{CNF}-(\mathrm{G} 1+\mathrm{G} 3)$ cell with sulfur loading of $20 \mathrm{mg} \mathrm{cm}^{-2}$, even though the typical behavior of a sulfur cathode was confirmed at a C-rate below $0.0075 \mathrm{C}$ with a discharge capacity of $1255 \mathrm{mAh} \mathrm{g}_{\text {sulfur }}{ }^{-1}\left(29 \mathrm{mAh} \mathrm{cm}^{-2}\right)$, the cells almost did not work at $0.01 \mathrm{C}$-rate. The difference is attributed to the ionic path in the sulfur cathode. It is well known that KB has a hollow structure, which allows it to retain a large amount of the liquid electrolyte. Therefore, KB enhanced the ionic conductivity in the sulfur cathode, reducing its overvoltage because of the ionic path in the sulfur cathode. Such high overvoltage can be reduced by a highly ionically conductive electrolyte. The discharge curves of the CNF-(DOL+DME) cell with sulfur loading of $20 \mathrm{mg} \mathrm{cm}^{-2}$ is shown in Fig. 1(c). Owing to the high ionic conductivity of the DOL+DME electrolyte, the typical behavior of a sulfur cathode was clearly observed even at $0.2 \mathrm{C}$ -

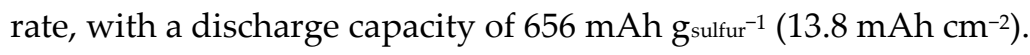


(a)

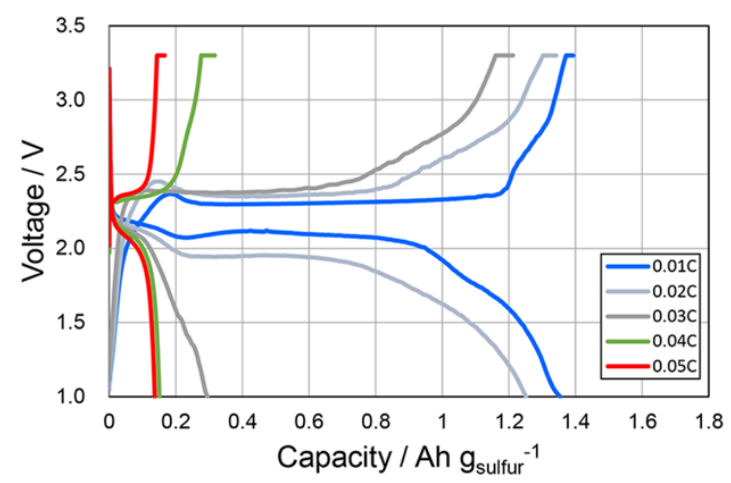

(b)

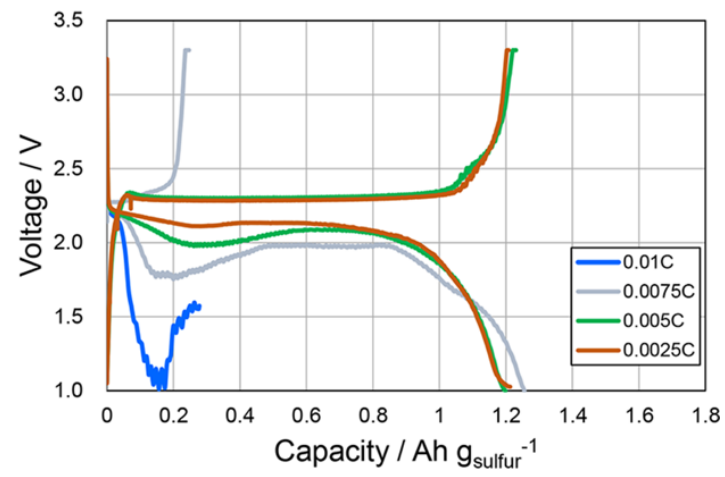

(c)

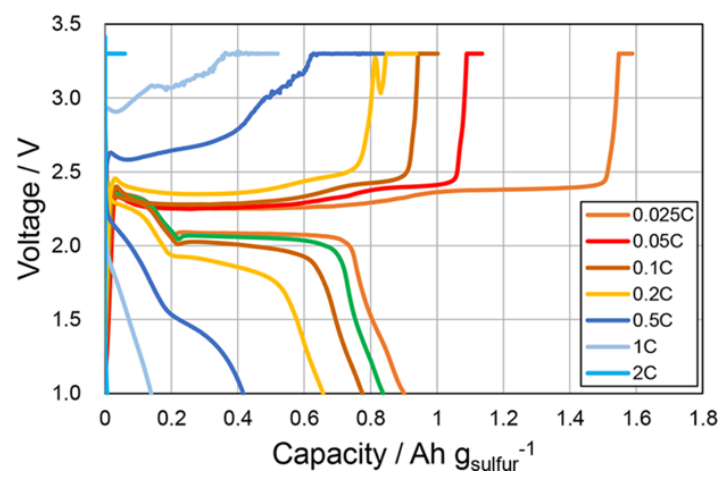

Figure 1. Charge-discharge curves with various C-rates of (a) KB-(G1+G3) cell with sulfur loading of $15 \mathrm{mg} \mathrm{cm}^{-2}$, (b) CNF-(G1+G3) cell with sulfur loading of $20 \mathrm{mg} \mathrm{cm}^{-2}$, and (c) CNF-(DOL+DME), cell with sulfur loading of $20 \mathrm{mg} \mathrm{cm}^{-2}$. Either $\mathrm{KB}$ or CNFs were used as the electroconductive additive, and either $\mathrm{G} 1+\mathrm{G} 3$ or DOL+DME was used as the electrolyte.

Fig. 2(a) and (b) summarize the gravimetric discharge capacity against the C-rate of the KB$(\mathrm{G} 1+\mathrm{G} 3), \mathrm{CNF}-(\mathrm{G} 1+\mathrm{G} 3)$, and $\mathrm{CNF}-(\mathrm{DOL}+\mathrm{DME})$ cells. The discharge capacity decreased with increasing C-rate for all the cells. For the KB- $(\mathrm{G} 1+\mathrm{G} 3)$ cells, even though the gravimetric capacity of the cell consisting of a cathode with sulfur loading of $2 \mathrm{mg} \mathrm{cm}^{-2}$ gradually decreased with increasing C-rate, the gravimetric capacity of the cell consisting of a cathode with sulfur loading of $15 \mathrm{mg} \mathrm{cm}^{-2}$ rapidly decreased after the $\mathrm{C}$-rate reached $0.025 \mathrm{C}$. On the other hand, the gravimetric capacity of the CNF-(G1+G3) cell consisting of a cathode with sulfur loading of $20 \mathrm{mg}_{\text {sufur }} \mathrm{cm}^{-2}$ rapidly decreased as soon as the C-rate reached $0.0075 \mathrm{C}$. As mentioned above, the difference in capacity is attributed to the ionic path in the sulfur cathodes owing to the hollow structure of KB. For the CNF-(DOL+DME) cell consisting of a cathode with sulfur loading of $2 \mathrm{mg} \mathrm{cm}^{-2}$, the gravimetric capacity gradually decreased with increasing C-rate. Note that the CNF-(DOL+DME) cell with sulfur loading of $2 \mathrm{mg}$ $\mathrm{cm}^{-2}$ worked even at a high $2 \mathrm{C}$-rate, with a gravimetric capacity of $610 \mathrm{mAh} \mathrm{g}_{\text {sulfur }}{ }^{-1}\left(2.1 \mathrm{mAh} \mathrm{cm}^{-2}\right)$ owing to the low viscosity and high ionic conductivity of the DOL+DME electrolyte system. In addition, the CNF-(DOL+DME) cell with sulfur loading of $40 \mathrm{mg} \mathrm{cm}^{-2}$ attained gravimetric capacities of 1094 and $758 \mathrm{mAh} \mathrm{g}_{\text {sulfur }}{ }^{-1}$ (46.8 and $32.4 \mathrm{mAh} \mathrm{cm}^{-2}$ ) at 0.05 and $0.1 \mathrm{C}$-rate, respectively. 
(a)

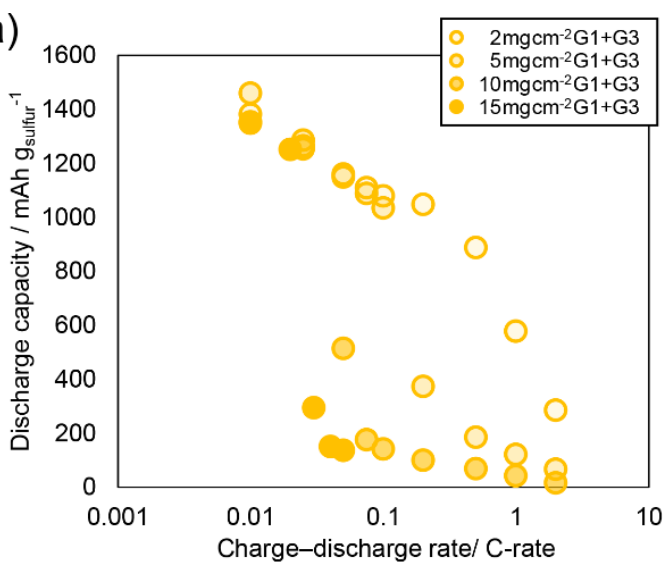

(c)

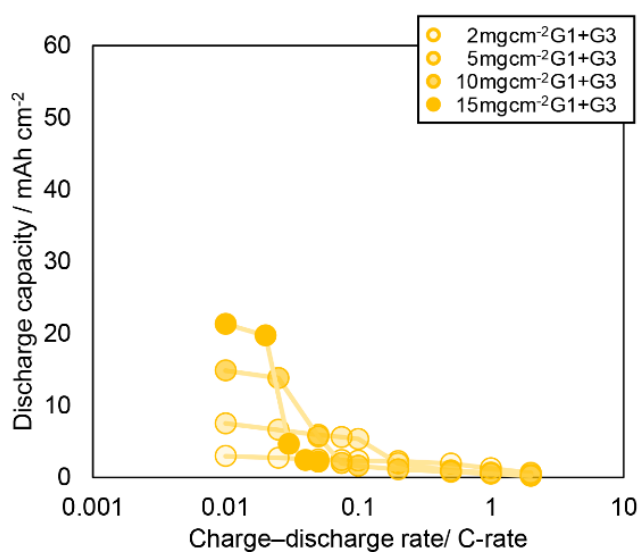

(b)

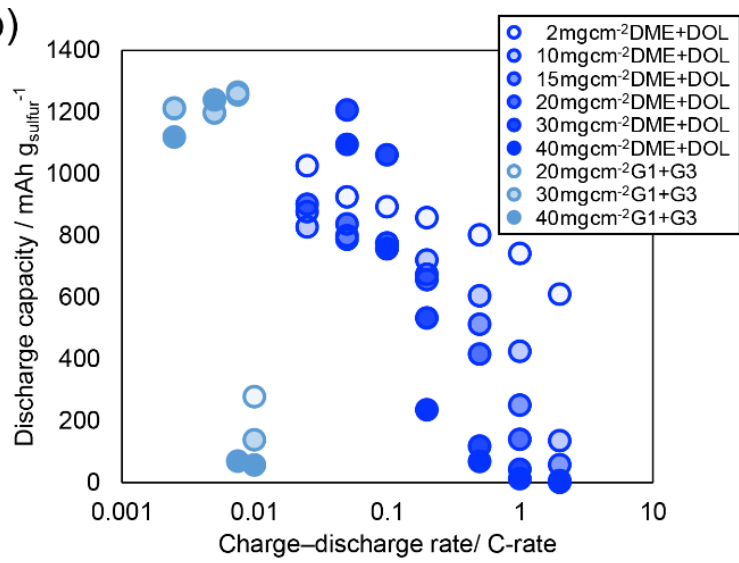

(d)

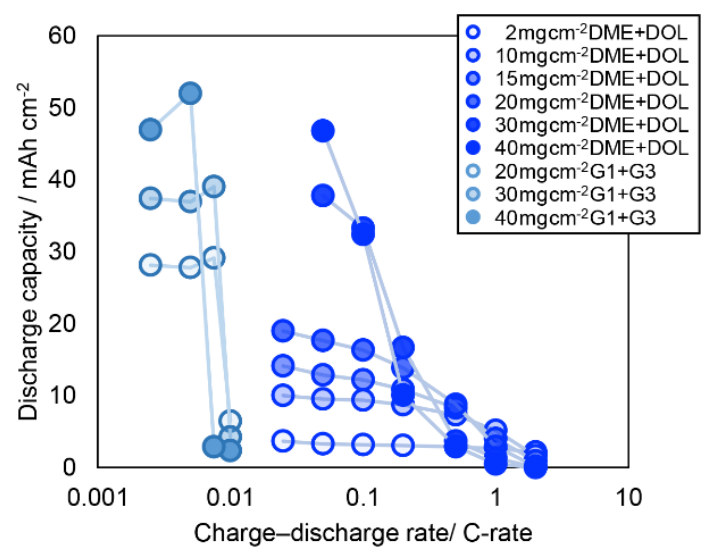

Figure 2. $(a, b)$ Gravimetric discharge capacity and $(c, d)$ areal discharge capacity versus $C$-rate of $(a$, c) KB-(G1+G3) cell, (b, d) CNF-(G1+G3) cell and CNF-(DOL+DME) cell. Either KB or CNFs were used as the electroconductive additive, and G1+G3 or DOL+DME was used as the electrolyte.

The plots of gravimetric discharge capacity versus the C-rate in Fig. 2(a) and (b) were converted into the plots of the areal discharge capacity versus the C-rate in Fig. 2(c) and (d). For all of the KB$(\mathrm{G} 1+\mathrm{G} 3)$, CNF-(G1+G3), and CNF-(DOL+DME) cells, as the sulfur loading in the cathode was increased, the areal capacity increased at lower C-rates (e.g., 0.02 C, 0.005 C, and 0.05 C). Interestingly, the areal discharge capacity converged to certain values as the $\mathrm{C}$-rate increased. Consequently, the areal discharge capacities of the $\mathrm{KB}-(\mathrm{G} 1+\mathrm{G} 3)$ cells converged to about $1 \mathrm{mAh} \mathrm{cm}^{-2}$ at $1 \mathrm{C}$-rate, the areal discharge capacities of the $\mathrm{CNF}-(\mathrm{G} 1+\mathrm{G} 3)$ cells converged to about $4 \mathrm{mAh} \mathrm{cm}^{-2}$ at $0.01 \mathrm{C}$-rate, and the areal discharge capacities of the CNF-(DOL+DME) cells converged to about $0.1 \mathrm{mAh} \mathrm{cm}^{-2}$ at $2 \mathrm{C}$-rate. However, a precise comparison of the values of areal capacity among the same systems and at the same C-rates showed that the areal discharge capacities were higher for cells with lower sulfur loading. This shows that the limitation for the high sulfur loading cathode at high C-rate operation was caused by ion diffusion in the bulk electrolyte. Ion diffusion in the pores of the sulfur cathode also limited operation at high C-rate. The limiting current densities, which were roughly estimated from the converged areal discharge capacities and their C-rate were 1, 0.04 , and $0.2 \mathrm{~mA} \mathrm{~cm}^{-2}$ for the KB-(G1+G3), CNF-(G1+G3), and CNF-(DOL+DME) systems, respectively. Even in the same solvent systems of $\mathrm{KB}-(\mathrm{G} 1+\mathrm{G} 3)$ and $\mathrm{CNF}-(\mathrm{G} 1+\mathrm{G} 3)$, rough estimates of the limiting current densities were different, which suggest that KB improved ion diffusion in the pores of the sulfur cathode owing to its hollow structure, resulting in a higher current density than that of the CNF system. In addition, in the same electroconductive additive systems of CNF-(G1+G3) and CNF-(DOL+DME), the limiting current density of the CNF-(DOL+DME) system was higher than that of the CNF-(G1+G3) system owing to the low viscosity of the DOL+DME electrolyte system. Thus, ion diffusion in the pores of the sulfur cathode account for one of the bottle-necks. However, ion diffusion in the bulk electrolyte was the principal bottle-neck, as confirmed by the convergence of the limiting current with increasing C-rate. 
Fig. 3 summarizes the gravimetric energy density obtained from single-layered full cells with the same amount of electrolyte as $260 \%$ of the theoretical vacancy of pores in the separator and the cathode layers. The gravimetric energy density was calculated from the weight of components of the cathode, anode, current collectors, electrolyte, and separator. The calculated values are represented by solid symbols in the figure. High sulfur loadings above $20 \mathrm{mg} \mathrm{cm}^{-2}$ were not obtained for the electroconductive materials of $\mathrm{AB}, \mathrm{CNTs}$, and $\mathrm{CNHs}$ because of the viscosities of their slurries were too high for filling into the aluminum foam. Although the KB-containing slurry was also high viscous for filling into the aluminum foam, it was possible for the aluminum foam to be filled with the slurry to the sulfur loading of $20 \mathrm{mg} \mathrm{cm}^{-2}$ with effort. Consequently, the electroconductive materials $\mathrm{AB}$, $\mathrm{CNTs}$, and CNHs could not improve the ionic diffusion in the cathode layer, resulting in very low gravimetric energy densities when they were used with glyme-based electrolytes. Because the sulfur loading of the cathodes containing $\mathrm{AB}, \mathrm{CNTs}$, and $\mathrm{CNHs}$ as additives was insufficient to obtain high areal capacity, the effect of the electrolytes was not evaluated. These sulfur cathodes did not succeed in enhancing the energy density probably because of inadequate formation of electron paths and iondiffusion paths. The KB-containing sulfur cathode was able to work to enhance the energy density even when a glyme-based electrolyte was used because of the well-formed ion-diffusion paths. As mentioned above, a CNF-containing sulfur cathode with high sulfur loading was successfully obtained; however, the aluminum foam with thickness of $1 \mathrm{~mm}$ was saturated at a sulfur loading of $\sim 20 \mathrm{mg} \mathrm{cm}^{-2}$. Therefore, aluminum foams with thickness of $1.4 \mathrm{~mm}$ (plotted as triangles) and $2.0 \mathrm{~mm}$ (plotted as squares) were filled with the appropriate slurries to obtain sulfur loadings of $\sim 30$ and $\sim 40$ $\mathrm{mg} \mathrm{cm}{ }^{-2}$, respectively. The C-rate capability of the CNF-containing sulfur cathode in the glyme-based electrolyte was lower than that of the KB-containing sulfur cathode. Therefore, the ether-based electrolyte was used for the CNF-containing sulfur cathode. Because of its high sulfur loading, energy densities of $\sim 120 \mathrm{Wh} \mathrm{kg}^{-1}$ were obtained for sulfur loadings of $\sim 30$ and $\sim 40 \mathrm{mg} \mathrm{cm}^{-2}$. According to our preliminary survey, the amount of electrolyte could be reduced to the volume of $100 \%$ of the theoretical vacancies for pores in the separator and cathode layers, without a noticeable decrease in charge-discharge characteristics. Therefore, the estimated energy densities, which were calculated based on the assumption that the amount of electrolyte was reduced from the amount for $260 \%$ of the pores to that for $100 \%$ of the pores, are also represented by dashed symbols in Fig. 3 . Consequently, a single-layered lithium-sulfur battery with energy densities of 360 and $392 \mathrm{Wh} \mathrm{kg}^{-1}$ were estimated for sulfur loadings of $\sim 30$ and $\sim 40 \mathrm{mg} \mathrm{cm}^{-2}$, respectively. Furthermore, we expect to be able to obtain an estimated energy density of $522 \mathrm{Wh} \mathrm{kg}^{-1}$ from the sum of the energy densities of a lithium-sulfur battery with six layers of active materials. 


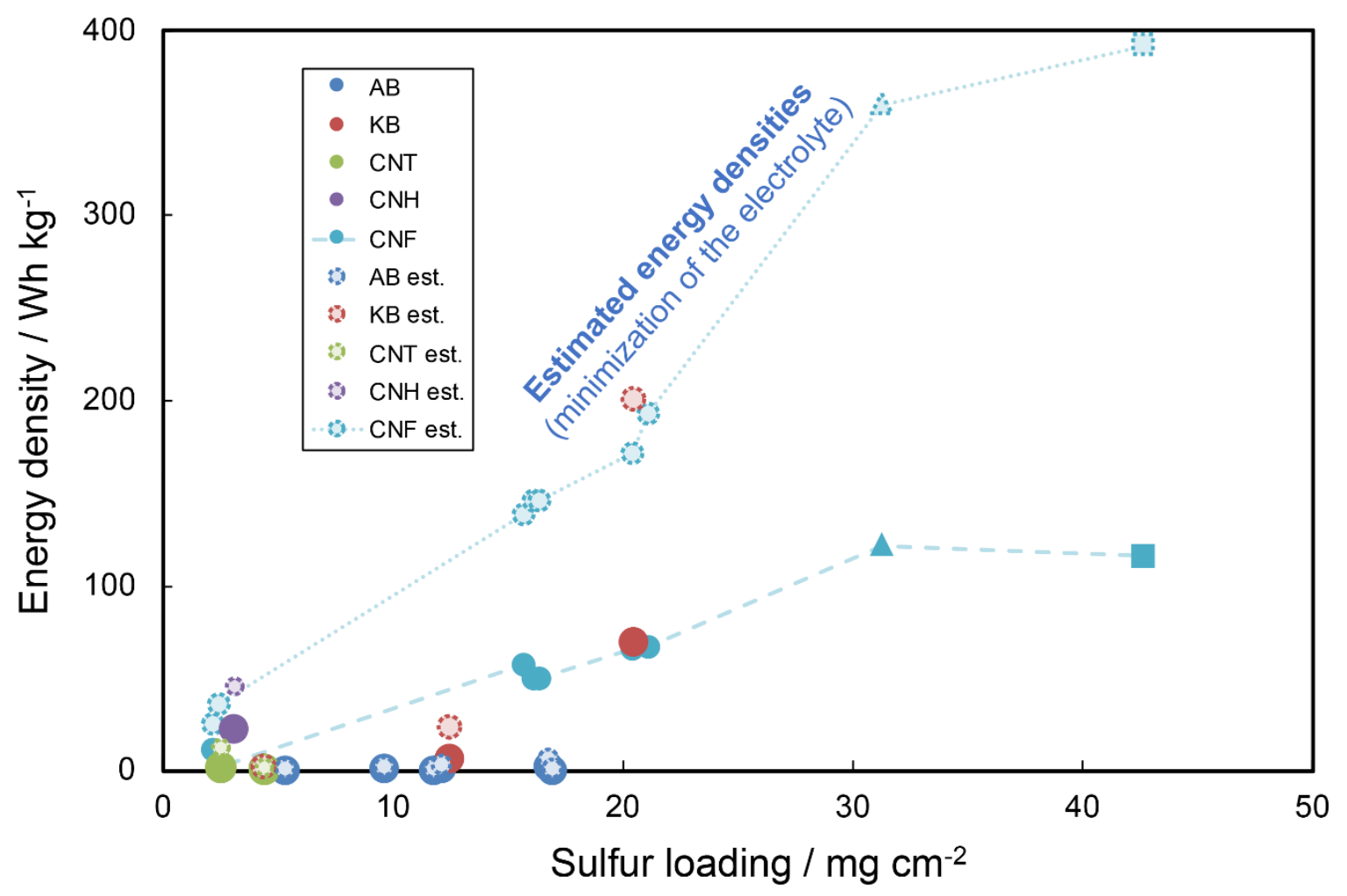

Figure 3. Gravimetric energy density obtained experimentally (solid symbols) and estimated computationally from the experimental data (dashed symbols) of the cells composed of various electroconductive additives and electrolytes as functions of sulfur loading. The cells used to obtain the experimental energy density contained $260 \%$ of the theoretical vacancy of electrolytes. To calculate the estimated energy density, the amount of the electrolyte in each cell was assumed to be $100 \%$ of the theoretical vacancy. The weight used to calculate the energy density included the weight of the cathode anode, current collectors, electrolyte, and separator. 


\section{Materials and Methods}

A sulfur-carbon-black composite was prepared by mixing sulfur powder (Sigma-Aldrich, Co., Japan) with Ketjenblack (KB; KB-EC-600JD, Lion Specialty Chemicals Co., Ltd., Japan), a type of electro-conductive carbon black, in a 6:4 weight ratio using a granulator (Balance Gran, AKIRAKIKO Co., Ltd., Japan). The mixture was then heated in a $\mathrm{N}_{2}$ atmosphere at a temperature of $155^{\circ} \mathrm{C}$ for 12 $\mathrm{h}$ to form a composite of sulfur and KB. Slurries for cathodes filling into an aluminum-foam current collector were prepared in the granulator by mixing the composite of sulfur and $\mathrm{KB}$ with an electroconductive additive: acetylene black (AB; DENKA BLACK Li, Denka Co., Ltd., Japan), KB, carbon nanotubes (CNTs; NC7000, Nanocyl SA, Belgium), carbon nanohorns (CNHs; CNHox, NEC Corporation, Japan), or carbon nanofibers (CNFs; VGCF, Showa Denko K.K., Japan); a binder consisting of CMC (Sigma-Aldrich, Co., Japan) and SBR (JSR Corporation, Japan), with a CMC/SBR weight ratio of 2:1; and distilled water as the solvent. The slurry was filled into three-dimensional (3D) structured aluminum foam (Celmet ${ }^{\mathrm{TM}}$, Sumitomo Electric Industries, Ltd., Japan) from both sides of the foam. The 3D structured aluminum foams were 1.0, 1.4, and $2.0 \mathrm{~mm}$ thick and had 550 $\mu \mathrm{m}$ pores 19. A full cell was assembled with a cathode consisting of S-KB on Al-foam, an anode consisting of $\mathrm{Li}$ metal on $\mathrm{Cu}$ foil, and an electrolyte consisting of a glyme-based or ether-based solution. Full cells with various dimensions and geometries were constructed for evaluation, such as coin-type $(\phi 9 \mathrm{~mm})$ and pouch-type $(3.0 \mathrm{~cm} \times 3.0 \mathrm{~cm}, 3.5 \mathrm{~cm} \times 7.0 \mathrm{~cm}$, and $7.0 \mathrm{~cm} \times 7.0 \mathrm{~cm})$. The glymebased electrolytes were composed of ethylene glycol dimethyl ether (monoglyme or G1; Kishida Chemical Co., Ltd., Japan), triethylene glycol diethyl ether (triglyme or G3; Kishida Chemical Co., Ltd., Japan), lithium bis(trifluoromethanesulfonyl)imide (LiTFSI; Kanto Chemical Co., Inc., Japan), and 1,1,2,2-tetrafluoroethyl 2,2,3,3-tetrafluoropropyl ether (HFE; DAIKIN Industries, Ltd., Japan). The glyme-based electrolyte (hereafter referred to as G1+G3) was a solvate ionic liquid mixture of [Li(G1)2][TFSI], [Li(G3)][TFSI], and HFE in a volume ratio of 1:1:8. In some cases, the glyme-based electrolyte was a solvate ionic liquid mixture of Li(G3)[TFSI] and HFE or Li(G4)[TFSI] (where G4 stands for tetraglyme or tetraethylene glycol dimethyl ether) and HFE in a volume ratio of 1:4. The ether-based electrolyte (hereafter referred to as DOL+DME) was composed of 1,3-dioxolane (DOL) and 1,2-dimethoxyethane (DME), and LiTFSI with the lithium molar concentration of $1 \mathrm{~mol} \mathrm{~L}^{-1}$. A polyolefin separator was soaked in each of the electrolytes, and the amount of electrolyte used was $260 \%$ of the theoretical vacancy of the cathode and the separator.

The viscosity of the slurries was measured using a viscosity meter (VM-100A, Sekonic Holdings Corporation, Japan).

The charge-discharge properties of the sulfur cathodes were evaluated with a cut-off voltage of 1.0-3.3 V, using a charge-discharge system (HJ1010SD8, Hokuto Denko Corp., Japan).

\section{Conclusions}

Various electroconductive additives, which are commercially available carbons, and electrolytes were evaluated in an attempt to improve the energy density and the C-rate capability of lithiumsulfur batteries consisting of a sulfur cathode and an aluminum-foam current collector. The slurry containing CNFs as an electroconductive additive exhibited low viscosity even at high solid ratio, attaining a sulfur loading of up to $40 \mathrm{mg} \mathrm{cm}^{-2}$ when injected into aluminum foam. Even for such high sulfur loading, relatively high C-rate capability was obtained by using an ether-based electrolyte, DOL+DME. For the sulfur cathode with a sulfur loading of $40 \mathrm{mg} \mathrm{cm}^{-2}$, gravimetric capacities of 1094 and $758 \mathrm{mAh} \mathrm{g}_{\text {sulfur }}{ }^{-1}$ (46.8 and $32.4 \mathrm{mAh} \mathrm{cm}^{-2}$ ) were obtained at 0.05 and $0.1 \mathrm{C}$-rate, respectively. In addition, the lithium-sulfur battery with high sulfur loading exhibited an energy density of $\sim 120 \mathrm{Wh}$ $\mathrm{kg}^{-1}$, which was calculated from the weight of the components of the cathode, anode, current collectors, electrolyte, and separator. By assuming that the amount of electrolyte can reduced from $260 \%$ of the pore volume to $100 \%$ of the pore volume, and by assuming that a six-layered lithiumsulfur battery has the accumulated density of six single-layered batteries, a theoretical energy density of $522 \mathrm{Wh} \mathrm{kg}^{-1}$ was obtained. Meanwhile, it was seen that even when high areal capacity was reached, the discharge capacity converged at a high C-rate unless there was an improvement in ion diffusion in the bulk electrolyte. 
Author Contributions: conceptualization, T.Y., H.M., S.T. and T.O.; experimental administration, H.N. and H.M.; data curation, H.N., writing - original draft preparation, H.N., writing - review and editing, T.Y.

Funding: This work is partly supported by Advanced Low Carbon Technology Research and Development Program Special Priority Research Area, "Next-Generation Rechargeable Battery," (ALCASpring) from the Japan Science and Technology Agency (JST), Japan (JPMJAL1301).

Acknowledgments: In this section you can acknowledge any support given which is not covered by the author contribution or funding sections. This may include administrative and technical support, or donations in kind (e.g., materials used for experiments).

Conflicts of Interest: The authors declare no conflict of interest.

\section{References}

(1) Nishi, Y. Lithium Ion Secondary Batteries; Past 10 Years and the Future. J. Power Sources 2001, 100 (12), 101-106.

(2) Hassoun, J.; Scrosati, B. A High-Performance Polymer Tin Sulfur Lithium Ion Battery. Angew. Chemie Int. Ed. 2010, 49 (13), 2371-2374. https://doi.org/10.1002/anie.200907324.

(3) Ji, X.; Lee, K. T.; Nazar, L. F. A Highly Ordered Nanostructured Carbon I [Ndash] I sulphur Cathode for Lithium I [Ndash] I sulphur Batteries. Nat. Mater. 2009, 8 (6), 500-506. https://doi.org/10.1038/nmat2460.

(4) Ellis, B. L.; Lee, K. T.; Nazar, L. F. Positive Electrode Materials for Li-Ion and Li-Batteries. Chem. Mater. 2010, 22 (3), 691-714. https://doi.org/10.1021/cm902696j.

(5) Wang, K. X.; Li, X. H.; Chen, J. S. Surface and Interface Engineering of Electrode Materials for LithiumIon Batteries. Adv. Mater. 2015, 27 (3), 527-545. https://doi.org/10.1002/adma.201402962.

(6) Zhou, G.; Li, L.; Ma, C.; Wang, S.; Shi, Y.; Koratkar, N.; Ren, W.; Li, F.; Cheng, H. M. A Graphene Foam Electrode with High Sulfur Loading for Flexible and High Energy Li-S Batteries. Nano Energy 2015, 11, 356-365. https://doi.org/10.1016/j.nanoen.2014.11.025.

(7) Zheng, G.; Yang, Y.; Cha, J. J.; Hong, S. S.; Cui, Y. Hollow Carbon Nanofiber-Encapsulated Sulfur Cathodes for High Specific Capacity Rechargeable Lithium Batteries. Nano Lett. 2011, 11 (10), 4462 4467. https://doi.org/10.1021/nl2027684.

(8) Hu, H.; Cheng, H.; Liu, Z.; Li, G.; Zhu, Q.; Yu, Y. In Situ Polymerized PAN-Assisted S/C Nanosphere with Enhanced High-Power Performance as Cathode for Lithium/Sulfur Batteries. Nano Lett. 2015, 15 (8), 5116-5123. https://doi.org/10.1021/acs.nanolett.5b01294.

(9) Nakamura, N.; Yokoshima, T.; Nara, H.; Momma, T.; Osaka, T. Suppression of Polysulfide Dissolution by Polypyrrole Modification of Sulfur-Based Cathodes in Lithium Secondary Batteries. J. Power Sources 2015, 274, 1263-1266. https://doi.org/10.1016/j.jpowsour.2014.10.192.

(10) Nakamura, N.; Wu, Y.; Yokoshima, T.; Nara, H.; Momma, T.; Osaka, T. Film Properties of Electropolymerized Polypyrrole for a Sulfur/Ketjenblack Cathode in Lithium Secondary Batteries. J.

Electrochem. Soc. 2016, 163 (5), A683-A689. https://doi.org/10.1149/2.0731605jes.

(11) Liang, X.; Hart, C.; Pang, Q.; Garsuch, A.; Weiss, T.; Nazar, L. F. A Highly Efficient Polysulfide Mediator for Lithium-Sulfur Batteries. Nat. Commun. 2015, 6, 5682.

https://doi.org/10.1038/ncomms6682.

(12) Wei Seh, Z.; Li, W.; Cha, J. J.; Zheng, G.; Yang, Y.; McDowell, M. T.; Hsu, P.-C.; Cui, Y. Sulphur-TiO2 Yolk-Shell Nanoarchitecture with Internal Void Space for Long-Cycle Lithium-Sulphur Batteries. Nat. Commun. 2013, 4, 1331. https://doi.org/10.1038/ncomms2327. 
(13) Dokko, K.; Tachikawa, N.; Yamauchi, K.; Tsuchiya, M.; Yamazaki, A.; Takashima, E.; Park, J.-W.; Ueno, K.; Seki, S.; Serizawa, N.; et al. Solvate Ionic Liquid Electrolyte for Li-S Batteries. J. Electrochem. Soc. 2013, 160 (8), A1304-A1310. https://doi.org/10.1149/2.111308jes.

(14) Cheng, L.; Curtiss, L. A.; Zavadil, K. R.; Gewirth, A. A.; Shao, Y.; Gallagher, K. G. Sparingly Solvating Electrolytes for High Energy Density Lithium-Sulfur Batteries. ACS Energy Lett. 2016, 1 (3), 503-509. https://doi.org/10.1021/acsenergylett.6b00194.

(15) Aurbach, D.; Pollak, E.; Elazari, R.; Salitra, G.; Kelley, C. S.; Affinito, J. On the Surface Chemical Aspects of Very High Energy Density, Rechargeable Li-Sulfur Batteries. J. Electrochem. Soc. 2009, 156 (8), A694. https://doi.org/10.1149/1.3148721.

(16) Hagen, M.; Dörfler, S.; Fanz, P.; Berger, T.; Speck, R.; Tübke, J.; Althues, H.; Hoffmann, M. J.; Scherr, C.; Kaskel, S. Development and Costs Calculation of Lithium-Sulfur Cells with High Sulfur Load and Binder Free Electrodes. J. Power Sources 2013, 224, 260-268. https://doi.org/10.1016/j.jpowsour.2012.10.004.

(17) Gao, J.; Abruña, H. D. Key Parameters Governing the Energy Density of Rechargeable Li/S Batteries. J. Phys. Chem. Lett. 2014, 5 (5), 882-885. https://doi.org/10.1021/jz5001819.

(18) Chen, A.; Liu, W.; Hu, H.; Chen, T.; Ling, B.; Liu, K. Facile Preparation of Ultrafine Ti ${ }_{4} \mathrm{O}_{7}$ Nanoparticle-Embedded Porous Carbon for High Areal Capacity Lithium-Sulfur Batteries. J. Mater. Chem. A 2018, 6 (41), 20083-20092. https://doi.org/10.1039/C8TA07511E.

(19) Nara, H.; Yokoshima, T.; Mikuriya, H.; Tsuda, S.; Momma, T.; Osaka, T. The Potential for the Creation of a High Areal Capacity Lithium-Sulfur Battery Using a Metal Foam Current Collector. J. Electrochem. Soc. 2017, 164 (1), A5026-A5030. https://doi.org/10.1149/2.0381701jes.

(20) Tachikawa, N.; Yamauchi, K.; Takashima, E.; Park, J.-W.; Dokko, K.; Watanabe, M. Reversibility of Electrochemical Reactions of Sulfur Supported on Inverse Opal Carbon in Glyme-Li Salt Molten Complex Electrolytes. Chem. Commun. 2011, 47 (28), 8157. https://doi.org/10.1039/c1cc12415c. 